\title{
Renal sodium handling in minimal change nephrotic syndrome
}

\author{
A-B BOHLIN AND U BERG \\ Department of Paediatrics, Karolinska Institute, Huddinge Hospital, Stockholm, Sweden
}

SUMmaRY Renal sodium handling was studied in 23 children at three different stages of the minimal change nephrotic syndrome-the oedema forming state, proteinuric steady state, and remission. Clearances of inulin and para-aminohippuric acid and urinary sodium excretion were determined basally, after intravenous infusion of isotonic saline and hyperoncotic albumin, and after furosemide injection. Absolute and fractional basal sodium excretion were significantly lower in oedema forming patients than in proteinuric patients in steady state, and non-proteinuric patients. In contrast to proteinuric patients in steady state and non-proteinuric patients, the oedema forming patients failed to respond to isotonic saline infusion with increased sodium excretion. After diuretic blockade with furosemide, the fractional sodium excretion of the oedema forming patients increased to values no different from those of the non-proteinuric patients, whereas the fractional sodium excretion of the steady state patients increased to significantly higher values. The plasma aldosterone concentration was within normal limits in 11 of 14 proteinuric patients, and did not correlate with the basal sodium excretion. Thus, sodium retention in the minimal change nephrotic syndrome was found only in oedema forming patients, and since this is not related to the plasma aldosterone concentration it may be caused by an intrarenal mechanism, probably sited in distal parts of the nephron.

That sodium is retained in patients with the nephrotic syndrome is well established, but the underlying mechanism is not clear. A common explanation is that the hypoalbuminaemia reduces the plasma oncotic pressure and results in hypovolaemia, thus stimulating the release of renin and aldosterone and leading to increased sodium reabsorption. ${ }^{1}$ Another possible mechanism might be an intrinsic inability of the nephrotic kidney to excrete sodium normally. ${ }^{2} 3$ We investigated renal sodium handling in children with the minimal change nephrotic syndrome during different stages of the disease.

\section{Patients and methods}

We studied 23 children ( 14 boys and nine girls) aged 2 to 15 years with minimal change nephrotic syndrome. The diagnosis was verified by renal biopsy in 21 patients. The remaining two children showed typical symptoms no different from those of the 21 who underwent biopsy and have now been in remission for more than two years. All patients had a clinical history of heavy proteinuria (greater than $40 \mathrm{mg} / \mathrm{m}^{2} /$ hour), hypoalbuminaemia (less than 25 $\mathrm{g} / \mathrm{l}$ ), and oedema. None of them had hypertension or persistent haematuria. Renal sodium handling was studied during the proteinuric phase (heavy proteinuria) and non-proteinuric phase (complete remission with normal serum albumin concentration). The patients in the proteinuric phase were divided into two subgroups - those with oedema formation and those in steady state. Oedema formation was defined as a weight gain during the three days preceding the study and none of the patients with oedema formation gained less than $0.6 \%$ of their body weight per day. All but one of the oedema forming patients were studied during their first episode of the nephrotic syndrome and only one was being treated with corticosteroids at the time of the investigation. The steady state patients had had a constant weight during the three days before the study. Six of the 12 patients in steady state were on daily corticosteroid treatment and one was being treated with a low dose on alternate days. Three of the 16 patients studied in the non-proteinuric phase were on low dose, alternate day corticosteroid treatment. No patient was treated with diuretic agents during the week before the study. In all the patients 
sodium intake was standardised at 70 to $100 \mathrm{mmol}$ $(\mathrm{mEq}) / \mathrm{m}^{2} / 24$ hours for at least three days before the study.

Basal urinary sodium excretion was investigated either in hydropenia after 17 hours of fluid deprivation or during water diuresis induced by the ingestion of $20 \mathrm{ml}$ water $/ \mathrm{kg}$ during the first hour and then $5 \mathrm{ml} / \mathrm{kg}$ every 30 minutes for another two hours. During the latter investigation clearances of inulin and para-aminohippuric acid were determined by a standard clearance technique including a continuous infusion of inulin (Inutest $25 \%$, LaevosanGesellschaft) $1.4 \mathrm{mg} / \mathrm{kg} /$ minute and para-aminohippuric acid (aminohippurate sodium, 20\%, MSD) $0.2 \mathrm{mg} / \mathrm{kg} /$ minute after a prime dose of $60 \mathrm{mg}$ inulin $/ \mathrm{kg}$ and $9 \mathrm{mg}$ para-aminohippuric acid/kg. After an equilibration time of one hour, urine was collected by spontaneous voiding every 30 minutes, and midway through each collection period a blood sample was drawn for analysis of sodium, inulin, and para-aminohippuric acid.

In the patients studied in hydropenia, the renal handling of sodium was further investigated during volume expansion and after diuretic blockade. Urine was collected by bladder catheterisation using a double lumen catheter (Argyle replogle tube, MAR 2565, size $10 \mathrm{Fr}$, length 24) with one external end connected to a vacuum pump. Throughout the investigation clearances of inulin and paraaminohippuric acid were determined as described above. After two 30 minute periods in hydropenia, volume expansion was started and urine was collected every 15 minutes throughout the investigation. Volume expansion was induced by intravenous infusion of isotonic saline $0.22 \mathrm{ml} / \mathrm{kg} /$ minute for 135 minutes corresponding to $30 \mathrm{ml} / \mathrm{kg}$. After infusion of $20 \mathrm{ml} / \mathrm{kg}$ an intravenous infusion of $20 \%$ salt poor human albumin was given to a total amount of $1 \mathrm{~g} / \mathrm{kg}$ over a period of 45 minutes. An intravenous injection of furosemide $1 \mathrm{mg} / \mathrm{kg}$ was given 15 minutes later. The investigation was then continued for another four sampling periods.
In 14 of the proteinuric patients the plasmas. aldosterone concentration was determined the dayọ. before the sodium handling study.

Urine and blood samples were analysed for inulin by the anthrone method ${ }^{4}$ and for para응 aminohippuric acid by a modifed Smith technique. Serum albumin concentrations were analysed by $a \frac{\bar{s}}{5}$ bromocresol green method. The concentration of sodium was determined by flame photometry. Then plasma aldosterone concentration was determined by a radioimmunological method with antibodies from either Cea Sorin or Diagnostic Products $\overrightarrow{-}$ Corporation. The body surface area was calculated according to Haycock ${ }^{6}$ from the height and weight of the patient when not oedematous.

Student's $t$ test and paired $t$ test and Wilcoxon'se rank sum test were used for statistical analysis. $A^{C}$ $P$ value less than 0.05 was accepted as indicating a d statistically significant difference.

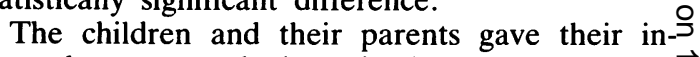
formed consent to the investigations. The study was $\overrightarrow{c s}$ approved by the ethical committee of the Karolinska专 Institute.

\section{Results}

Laboratory and renal functional data in the differege stages of the disease are shown in Table 1. Statistical $!^{+}$ analysis was not performed on the oedema forming patients studied during water diuresis because of the small number of patients. The glomerular filtrationo rates in hydropenia of the oedema forming patientsळ were significantly lower than those of the steady $\mathbb{Q}$ state and non-proteinuric patients. The glomerular $\overrightarrow{\vec{O}}$ filtration rates of the latter two groups of patients 3 did not differ significantly in hydropenia or water diuresis.

Table 1 also shows the absolute and fractional basal urinary sodium excretion. The mean absolute as well as the mean fractional urinary sodium: excretion during the oedema forming state was. significantly lower than that during steady state and

Table 1 Laboratory and renal functional data in different stages of minimal change nephrotic syndrome. The data are given as mean $(S D)$

\begin{tabular}{|c|c|c|c|c|c|c|c|}
\hline Stage of disease & $\begin{array}{l}\text { Stage of hydration } \\
\text { (No) }\end{array}$ & $\begin{array}{l}\text { Serum albumin } \\
(g / l)\end{array}$ & $\begin{array}{l}\text { Serum sodium } \\
\text { mmol }((m E q) / l)\end{array}$ & $\begin{array}{l}G F R \\
(\mathrm{ml} / \mathrm{min} / \\
\left.l \cdot 73 \mathrm{~m}^{2}\right)\end{array}$ & $\begin{array}{l}F F \\
(\%)\end{array}$ & $\begin{array}{l}U_{\mathrm{Na}} V \\
(\mu \mathrm{mol}(\mu E q) / \mathrm{min} / \\
\left.1.73 \mathrm{~m}^{2}\right)\end{array}$ & $\begin{array}{l}C_{N a} / C_{l n} \\
(\%)\end{array}$ \\
\hline $\begin{array}{l}\text { Oedema forming } \\
(n=7)\end{array}$ & $\begin{array}{l}\text { Hydropenia (4) } \\
\text { Water diuresis (3) }\end{array}$ & $\begin{array}{l}15(6) \\
18(10)\end{array}$ & $\begin{array}{l}137(2) \\
131(6)\end{array}$ & $\begin{array}{ll}58 & (22) \\
81 & (42)\end{array}$ & $\begin{array}{l}14 \cdot 7(3 \cdot 5) \\
16 \cdot 8(7 \cdot 2)\end{array}$ & $\begin{array}{l}13(18) \\
23(22)\end{array}$ & $\begin{array}{l}0.12(0 \cdot 11) \\
0 \cdot 12(0 \cdot 16)\end{array}$ \\
\hline $\begin{array}{l}\text { Steady state } \\
\quad(n=12)\end{array}$ & $\begin{array}{l}\text { Hydropenia (6) } \\
\text { Water diuresis (6) }\end{array}$ & $\begin{array}{ll}31 & (6) \\
22 & (8)\end{array}$ & $\begin{array}{l}141(3) \\
136(3)\end{array}$ & $\begin{array}{r}96(21) \\
112(8)\end{array}$ & $\begin{array}{l}17 \cdot 4(3 \cdot 2) \\
17 \cdot 0(2 \cdot 3)\end{array}$ & $\begin{array}{l}112(83) \\
135(72)\end{array}$ & $\begin{array}{l}0.87(0.51) \\
0.89(0.47)\end{array}$ \\
\hline $\begin{array}{l}\text { Remission } \\
(n=16)\end{array}$ & $\begin{array}{l}\text { Hydropenia (6) } \\
\text { Water diuresis (10) }\end{array}$ & $\begin{array}{l}43(2) \\
42(3)\end{array}$ & $\begin{array}{l}142(2) \\
138(3)\end{array}$ & $\begin{array}{l}109(13) \\
126(21)\end{array}$ & $\begin{array}{l}21 \cdot 2(3 \cdot 6) \\
21 \cdot 4(3 \cdot 8)\end{array}$ & $\begin{array}{l}127(50) \\
151(79)\end{array}$ & $\begin{array}{l}0.71(0.16) \\
0.90(0.52)\end{array}$ \\
\hline
\end{tabular}


remission. The sodium excretion of the proteinuric patients in steady state did not differ from that of the non-proteinuric patients.

Fig. 1 (a) and (b) shows the absolute and fractional urinary sodium excretion during hydropenia and after different degrees of volume expansion. After infusion of $20 \mathrm{ml}$ of isotonic saline $/ \mathrm{kg}$ the urinary sodium excretion during the oedema forming state did not change significantly from that during hydropenia. The sodium excretion during steady state and remission increased significantly over the values in hydropenia. The mean absolute sodium excretion did not differ between the two latter stages of disease after volume expansion, while the mean fractional sodium excretion during steady state was significantly higher than that during remission. After further volume expansion to $30 \mathrm{ml}$ of isotonic saline/ $\mathrm{kg}$ and hyperoncotic salt poor albu$\min (20 \%)$ no significant change in sodium excretion was seen in any stage of the disease, but the absolute sodium excretion of the patients in steady state turned out to be significantly higher than that of the non-proteinuric patients.

After diuretic blockade with furosemide (Table 2)

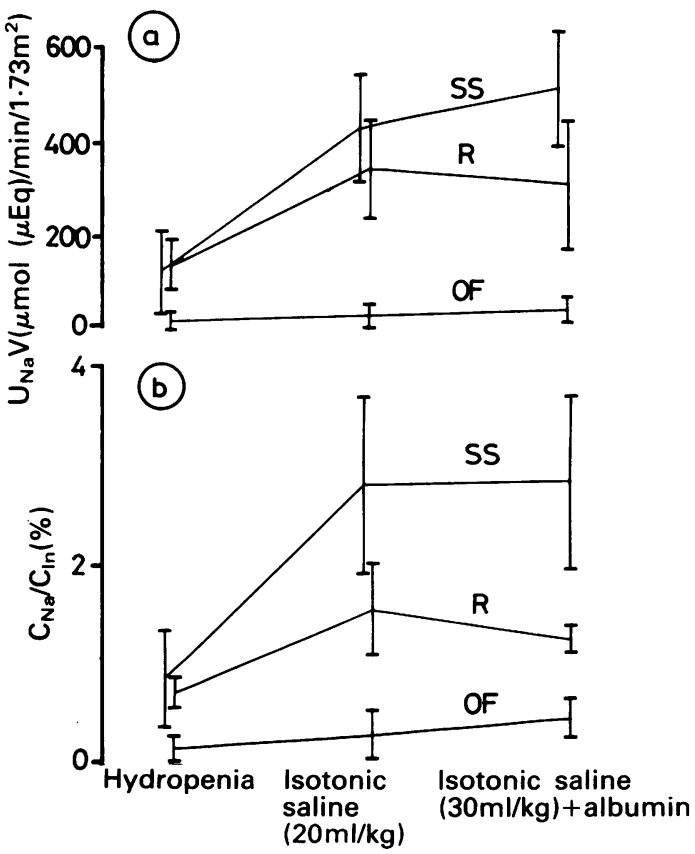

Fig. 1 (a) Absolute $\left(U_{N a} V\right)$ and (b) fractional $\left(C_{N a} / C_{I n}\right)$ urinary sodium excretion in the oedema forming state $(O F)$, proteinuric steady state (SS), and remission $(R)$ in hydropenia and after volume expansion with isotonic saline, $20 \mathrm{ml} / \mathrm{kg}$ and $30 \mathrm{ml} / \mathrm{kg}$ and hyperoncotic human albumin. Mean (SD) are indicated and connected with lines.
Table 2 Absolute $\left(U_{N a} V\right)$ and fractional $\left(C_{N a} / C_{I n}\right)$ urinary sodium excretion in different stages of the minimal change nephrotic syndrome after diuretic blockade with furosemide. Data are given as mean (SD)

\begin{tabular}{llll}
\hline $\begin{array}{l}\text { Stage of } \\
\text { disease }\end{array}$ & No & $\begin{array}{l}U_{\mathrm{Na}} \mathrm{V} \\
\left(\mu \mathrm{mol}(\mu \mathrm{Eq}) / \mathrm{min} / \mathrm{l} \cdot 73 \mathrm{~m}^{2}\right)\end{array}$ & $\begin{array}{l}C_{\mathrm{Na}} / C_{\mathrm{In}} \\
(\%)\end{array}$ \\
\hline $\begin{array}{l}\text { Oedema-forming } \\
\text { Steady state }\end{array}$ & 4 & $2912(1208)$ & $21.4(8.6)$ \\
Remission & 6 & $5510(1228)$ & $29.7(6 \cdot 2)$ \\
\hline
\end{tabular}

the fractional urinary sodium excretion of the oedema forming patients increased to values comparable with those in remission. The fractional sodium excretion of the steady state patients increased to values significantly higher than those of the non-proteinuric patients. The absolute urinary sodium excretion was significantly lower during the oedema forming state, compared with the excretion during steady state which did not differ from that during the non-proteinuric phase. All patients studied had a urine osmolality equal to the blood osmolality after the furosemide injection.

The amount of sodium accumulated during the intravenous saline load of $30 \mathrm{ml} / \mathrm{kg}$ was mean (SD) $5.1(0 \cdot 2) \mathrm{mmol}(\mathrm{mEq}) / \mathrm{kg}$ in the oedema forming patients; significantly more than that of the patients in steady state $(4.1(0.5) \mathrm{mmol}(\mathrm{mEq}) / \mathrm{kg})$ and in remission $(3.9(0.5) \mathrm{mmol}(\mathrm{mEq}) / \mathrm{kg})$.

Fig. 2 shows the plasma aldosterone concentration in relation to the basal urinary sodium excretion

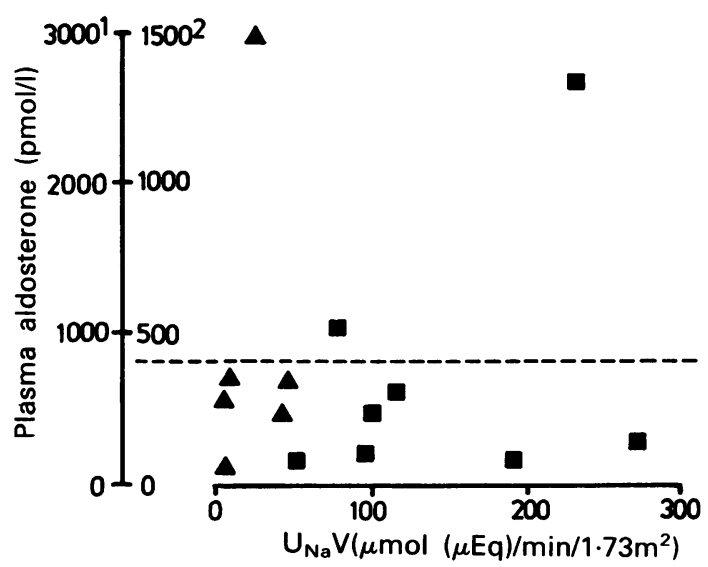

Fig. 2 Plasma aldosterone concentration in relation to basal urinary sodium excretion $\left(U_{N a} V\right)$ in 14 proteinuric patients, six oedema forming ones $(\Delta)$ and eight patients in steady state $(\mathbf{\square})$.

The horizontal line shows the upper normal limit. Radioimmunological method with antibodies from ${ }^{1}$ Cea Sorin or ${ }^{2}$ Diagnostic Products Corporation. 
in the proteinuric patients. One of six oedema forming patients and two of eight steady state patients had raised plasma aldosterone concentrations. No correlation was found between plasma aldosterone concentration and basal urinary sodium excretion.

\section{Discussion}

The increased sodium accumulation and the low basal urinary sodium excretion found in the oedema forming patients confirm the presence of the sodium retention known to occur in the nephrotic syndrome. The proteinuric patients in steady state, however, did not show increased sodium accumulation and exhibited no decrease in urinary sodium excretion compared with the non-proteinuric patients, suggesting that the sodium retention had ceased or that the retaining mechanisms had been compensated for. The low urinary sodium excretion in the oedema forming patients could be due to either a decreased filtered load or increased tubular sodium reabsorption, or both. The filtered sodium load was, in fact, decreased in the oedema forming patients since the glomerular filtration rates and the serum sodium concentrations were low (Table 1). The low filtered load, however, cannot be the only mechanism responsible for the sodium retention, since the fractional sodium excretion was low (Table 1). Thus, in the oedema forming state, sodium reabsorption must be increased somewhere in the nephron.

To investigate further the renal handling of sodium, some of the patients were given a saline infusion to attain a moderate volume expansion. A hyperoncotic albumin infusion was then given to increase the oncotic pressure in the peritubular capillaries and, finally, an intravenous furosemide injection was given to block the sodium reabsorption in the thick ascending limb of the loop of Henle and the early distal convoluted tubule (the diluting segment). The renal sodium response of the nonproteinuric patients to the volume expansion conformed with that found in normal subjects. ${ }^{7}$ The natriuresis after volume expansion has been attributed to redistribution of the renal circulation, ${ }^{8}$ or to inhibited proximal tubular sodium reabsorption caused by either changes in physical factors in the peritubular capillaries ${ }^{9-11}$ or a natriuretic factor. ${ }^{12}$ The hyperoncotic albumin infusion might add a further natriuretic effect of volume expansion that can be counteracted by an increase in the peritubular capillary oncotic pressure, leading to increased proximal sodium reabsorption. ${ }^{1013}$ Thus, there was no change in sodium excretion in the nonproteinuric patients when the saline volume expan- sion was increased from 20 to $30 \mathrm{ml} / \mathrm{kg}$ and the albumin infusion was given.

The cause of the inability of the oedema forming patients to respond to volume expansion witep natriuresis cannot be fully clarified from the presen $\bar{\varphi}$ results. One possible explanation would be hypovo laemia leading to insufficient volume expansion b the saline infusion. Hypovolaemia seems improb 8 able, however, since the plasma volume was deter mined before starting the renal function test in three. of the oedema forming patients and was $93 \%$. $129 \%$, and $133 \%$ of estimated normal values (unpublished data). Furthermore, Geers and colleagues found normal or increased blood volumes to be th\&े rule in the nephrotic syndrome. ${ }^{14}$ On the basis of experimental studies in puromycin induced nephrof sis in the rat, Favre and Gourjon explained the absence of a natriuretic response to acute salini volume expansion in terms of an inability to produce the natriuretic factor. ${ }^{15}$ This explanation cannot be ruled out in our patients. Bourgoignie found evi-s dence of a lack of a natriuretic factor in uraemi® patients with the nephrotic syndrome in contrast to those without the nephrotic syndrome. ${ }^{16} \mathrm{~A}$ lack o redistribution of renal blood flow to cortical, les@ sodium retaining, nephrons after volume expansion. might be contributory to the absence of natriuregis 50 A decrease in the ratio of outer cortical to intigef cortical blood flow was shown by Banks to esists under basal conditions in aminonucleoside nephros sis in the rat. ${ }^{17} \mathrm{~A}$ decrease in oncotic pressure in th peritubular capillaries is thought to be one physica factor contributing to the increased sodium excre⿻ tion after volume expansion. ${ }^{9}$ The peritubular onco $\frac{\vec{t}}{\overrightarrow{6}}$ tic pressure in hypoalbuminaemic patients is alread low. In a previous study we found the distal tubulat sodium delivery of nephrotic children to be inversel correlated with the serum albumin concentration, $\frac{1}{2}$ which indicates decreased proximal tubular sodiurg reabsorption in the most hypoalbuminaemio patients. A low proximal sodium reabsorption wa? also reported by Grausz in a study of nephrotig adults $^{19}$ and by Bernard ${ }^{20}$ and Ichikawa $^{3}$ in ex perimental studies in nephrotic rats. A furtheo inhibition of the already low proximal tubula sodium reabsorption may occur in volume expane sion but since the urinary sodium excretion did not. increase, this possible effect must be masked bo increased sodium reabsorption in more distal parts of the nephron.

The dose of furosemide given seems to have bee sufficient to block the sodium chloride reabsorption completely in the diluting segment in all patients since isosmotic urine was produced by all patient $\$ 2$ After furosemide injection the fractional sodium excretion of the oedema forming patients increase 
to values no different from those in the nonproteinuric phase, which indicates an intact sodium reabsorption in the diluting segment. The lower absolute urinary sodium excretion in the oedema forming state is explained by the low filtered load.

The site of the increased sodium reabsorption in the oedema forming state cannot be fully clarified from the present results. A site distal to the diluting segment seems most probable, however, since the response to furosemide was not increased in oedema forming compared with non-proteinuric patients. Thus, increased sodium reabsorption in the proximal tubules and the diluting segment is unlikely. Furthermore, evidence of decreased proximal sodium reabsorption has been reported. ${ }^{18} 19$ In experimental studies on unilateral nephrosis in the rat, Ichikawa found that the renal salt retention was due to intrarenal factors localised beyond the distal convolution, ${ }^{3}$ and Bernard, in his experimental model, localised the increased sodium reabsorption to the collecting ducts. ${ }^{20}$

There were no signs of sodium retention in the proteinuric patients in steady state. Increased sodium excretion after furosemide injection in these patients indicates an increased sodium reabsorption in the diluting segment probably secondary to a decreased proximal sodium reabsorption-possible since the serum albumin concentrations were low (Table 1).

Studies on the influence of glucocorticosteroids on renal sodium excretion have documented a natriuretic effect. ${ }^{21}$ This effect has been attributed to a raised glomerular filtration rate increasing the filtered load, thereby obscuring the other effect of corticosteroids, viz the increased tubular sodium reabsorption. ${ }^{22}$ Experimental studies on hypophysectomised rats indicate that corticosteroids have no influence on ${ }^{23}$ or diminish the natriuretic response to saline infusion. ${ }^{24}$ In the present study six out of the 12 patients in steady state were on daily corticosteroid treatment; but there was no difference in the renal sodium excretion between the treated and the untreated patients. Thus, the corticosteroids could not explain the high or increased sodium excretion in the steady state patients.

The role of the renin-angiotensin-aldosterone system in the sodium retention of the nephrotic syndrome has been widely discussed. $\mathrm{High}^{25-28}$ as well as normal ${ }^{29}$ urine and plasma aldosterone concentrations have been reported. In this study only three of 14 proteinuric patients had raised plasma aldosterone concentrations not correlating with the urinary sodium excretion. Therefore, although increased concentrations of aldosterone may contribute to sodium retention, this hormone cannot be the only, or even the major, cause of the salt accumulation.$^{30}$ Instead, the present results support the concept of an intrarenal sodium retaining factor. Such a factor has been suggested by Ichikawa, ${ }^{3}$ since in his experimental model sodium was retained solely in the proteinuric kidney in unilateral nephrosis.

In conclusion, sodium retention in the minimal change nephrotic syndrome is found only in the oedema forming proteinuric patients and seems to be caused by an intrarenal mechanism acting in parts of the nephron distal to the diluting segment.

\section{References}

Metcoff J, Janeway CA. Studies on the pathogenesis of nephrotic edema. J Pediatr 1961;58:640-85.

2 Brown EA, Markandu ND, Roulston JE, Jones BE, Squires M, MacGregor GA. Is the renin-angiotensin-aldosterone system involved in the sodium retention in the nephrotic syndrome? Nephron 1982;32:102-7.

3 Ichikawa I, Rennke HG, Hoyer JR, et al. Role for intrarenal mechanisms in the impaired salt excretion of experimental nephrotic syndrome. J Clin Invest 1983;71:91-103.

${ }^{4}$ Hilger HH, Klümper JD, Ullrich KJ. Wasserrückresorption und Ionentransport durch die Sammelrohrzellen der Säugetierniere. Pflugers Arch 1958;267:218-37.

${ }^{5}$ Smith HW, Finkelstein N, Aliminosa L, Crawford B, Graber M. The renal clearances of substituted hippuric acid derivatives and other aromatic acids in dog and man. J Clin Invest 1945;24:388-404.

${ }^{6}$ Haycock GB, Schwartz GJ, Wisotsky DH. Geometric method for measuring body surface area: a height-weight formula validated in infants, children, and adults. $J$ Pediatr 1978;93: 62-6.

${ }^{7}$ Crawford B, Ludemann $\mathrm{H}$. The renal response to intravenous injection of sodium chloride solutions in man. J Clin Invest 1951;30:1456-62.

${ }^{8}$ Lameire NH, Lifschitz MD, Stein JH. Heterogeneity of nephron function. Annu Rev Physiol 1977;39:159-84.

${ }^{9}$ Martino JA, Earley LE. Demonstration of a role of physical factors as determinants of the natriuretic response to volume expansion. J Clin Invest 1967;46:1963-78.

10 Brenner BM, Falchuk KH, Keimowitz RI, Berliner RW. The relationship between peritubular capillary protein concentration and fluid reabsorption by the renal proximal tubule. J Clin Invest 1969;48:1519-31.

"Ott CE. Effect of saline expansion on peritubule capillary pressures and reabsorption. Am J Physiol 1981;240:F106-10.

12 DeWardener HE. Natriuretic hormone. Clinical Science and Molecular Medicine 1977;53:1-8.

13 Spitzer A, Windhager EE. Effect of peritubular oncotic pressure changes on proximal tubular fluid reabsorption. Am J Physiol 1970;218:1188-93.

14 Geers AB, Koomans HA, Boer P, Dorhout Mees EJ. Plasma volume measurements in patients with nephrotic syndrome: a methodological study on the labeled albumin method. Kidney Int 1983;23:123a.

15 Favre H, Gourjon M. Absence of production of natriuretic factor following acute saline expansion in nephrotic rats. Clin Sci 1982;63:317-9.

${ }^{16}$ Bourgoignie JJ, Hwang KH, Ipakchi E, Bricker NS. The presence of a natriuretic factor in urine of patients with chronic uremia. The absence of the factor in nephrotic uremic patients. J Clin Invest 1974;53:1559-67.

17 Banks RO, Pesce AJ, Ooi BS, Pollak VE. Effect of aminonucleoside on transport maximum of para-aminohippurate and 
intrarenal blood flow distributions in rats. $J$ Lab Clin Med 1977;90:341-6.

18 Bohlin A-B, Berg U. Renal water handling in minimal change nephrotic syndrome. Int J Pediatr Nephrol 1984; June.

${ }^{19}$ Grausz H, Lieberman R, Earley LE. Effect of plasma albumin on sodium reabsorption in patients with nephrotic syndrome. Kidney Int 1972:1:47-54.

20 Bernard DB, Alexander EA, Couser WG, Levinsky NG. Renal sodium retention during volume expansion in experimental nephrotic syndrome. Kidney Int 1978;14:478-85.

${ }^{21}$ Pechet MM, Bowers B, Bartter FC. Metabolic studies with a new series of 1,4-diene steroids. II. Effects in normal subjects of prednisone, prednisolone, and $9 \alpha$-fluoroprednisolone. J Clin Invest 1959;38:691-701.

${ }^{22}$ Garrod O, Davies SA, Cahill G, Jr. The action of cortisone and desoxycorticosterone acetate on glomerular filtration rate and sodium in water exchange in the adrenalectomized dog. J Clin Invest 1955;34:761-76.

${ }^{23}$ Banks RO. Natriuresis and kaliuresis in saline-expanded, long-term hypophysectomized rats. Proc Soc Exp Biol Med 1983;172:502-7.

${ }^{24}$ Lichardus B, Ponee J. On the role of the hypophysis in the renal mechanism of body fluid volume regulation. Endokrinologie 1973;61:403-12.

${ }^{25}$ Luetscher JA, Jr, Johnson BB. Chromatographic separation of the sodium-retaining corticoid from the urine of children with nephrosis, compared with observations on normal children. J Clin Invest 1954:33:276-86.

26 Oliver WJ. Physiologic responses associated with steroidinduced diuresis in the nephrotic syndrome. J Lab Clin Med 1963;62:449-64.

27 Medina A, Davies DL, Brown JJ, et al. A study of the renin-angiotensin system in the nephrotic syndrome. Nephron 1974;12:233-40.

28 Meltzer JI, Keim HJ, Laragh JH, Sealey JE, Jan K-M, Chien S. Nephrotic syndrome: vasoconstriction and hypervolemic types indicated by renin-sodium profiling. Ann Intern Med 1979:91:688-96.

${ }^{29}$ Chonko AM, Bay WH, Stein JH, Ferris TF. The role of renin and aldosterone in the salt retention of edema. Am J Med 1977;63:881-9.

30 Levy M, Seely JF. Pathophysiology of edema formation. In: Brenner BM, Rector FC, Jr, eds. The kidney. 2nd ed, volume I. Philadelphia: WB Saunders, 1981:734.

Correspondence to Dr A-B Bohlin, Department of Paediatrics, Huddinge Hospital, S-141 86 Huddinge, Sweden.

Received 29 May 1984

\section{Commentary}

\section{E A BROWN}

Department of Medicine, Charing Cross Hospital Medical School, London

Nephrotic syndrome is defined as oedema accompanied by proteinuria and hypoalbuminaemia, the oedema formation being due to retention ot sodium by the kidney. The classic teaching is that this sodium retention is caused by stimulation of th尺 renin-angiotensin-aldosterone system by the low blood volume caused by the low plasma oncoti pressure. There is, however, mounting evidence that this theory is incorrect and that some othe? mechanism, possibly intrarenal, is reponsible for the sodium retention. There are now many studies showing that plasma aldosterone, plasma reni\& activity, and blood volume may be low, normal, of high in patients with nephrotic syndrome whi's they are retaining sodium. Furthermore, sodium reten= tion continues even after blockade of the renin angiotensin-aldosterone system by captopril.

The paper by Bohlin and Berg in this issuo confirms the lack of correlation between plasm aldosterone and urinary sodium excretion. The authors also show that there was no change ifo urinary sodium excretion in patients retaining sodium when acutely volume expanded with albu min. This is in keeping with other studies showing that many patients continue to retain sodium wheB given albumin for many days despite profoun 8 suppression of the renin-angiotensin-aldosteron $\Phi$ system.

The actual mechanism of the sodium retention o甲 nephrotic syndrome, however, remains unclear. The finding of decreased sodium excretion only by affected kidney in the model of unilateral aminonucleoside induced nephrosis in the rat suggests that sodium retention may well be due to an intrarenas mechanism. What this intrarenal mechanism is however, remains unknown.

Even the site of the increased sodium reabsorp tion is not fully established. This study favours th $\vec{f}$ distal tubule yet there are other studies suggesting that proximal sodium reabsorption may be in? creased.

If an intrarenal mechanism is the cause of sodiuna retention in nephrotic syndrome, why is the renin? angiotensin-aldosterone system stimulated in some of the patients and not in others? The most likely. explanation is that those patients with more severe hypoalbuminaemia develop a low blood volumeె which stimulates renin release. In normal subjects, $\$$ diminution of blood volume and stimulation of the renin system is a potent mechanism causing sodium? retention by the kidney. In nephrotic patients however, there seems to be an overriding mechan? ism, probably intrarenal, causing sodium retention independent of the renin system. The findings of Bohlin and Berg provide further support for thise theory. 